\title{
Split double factorial with additional treatment and the post-harvest of Niagara grapes
}

\author{
Experimentos fatoriais duplos subdivididos com tratamento adicional \\ e a pós-colheita de uvas Niágara
}

Pórtya Piscitelli Cavalcanti ${ }^{\mathrm{I}}$ Eric Batista Ferreira ${ }^{\mathrm{I}{ }^{*}}$ Laís Brambilla Storti $^{\mathrm{II}}$

\section{ABSTRACT}

This study aims to discuss and explain how to deal with the analysis of experiments conducted in completely randomized design (CRD) and subdivided into double factorial with additional treatment in the plot. In addition it was illustrate the discussion by analyzing data from an experiment on post-harvest of Niagara grapes. The sums of squares for each source of variation are presented, while discussing how the additional treatment affects the whole variation. Niagara grapes were treated in the pre-harvest with three preservatives (calcium chloride, calcium nitrate and calcium lactate) at $0 \%, 0.5 \%, 1 \%$ and $2 \%$ and stored for $0,10,20$ and 30 days. All the preservatives evaluated at $0 \%$ represented the control (additional) treatment.

Key words: analysis of variance, software $R$, experimental statistics.

\section{RESUMO}

Este trabalho tem como objetivos discutir e explicitar como se dá a análise de experimentos conduzidos em delineamento inteiramente casualizado (DIC) e esquema fatorial duplo subdividido com tratamento adicional na parcela, além de ilustrar a discussão com um experimento de pós-colheita de uvas Niágara. São apresentadas as somas de quadrados de cada fonte de variação, enquanto se discute como o tratamento adicional afeta a variação total. Uvas Niágara foram tratadas napré-colheita com os seguintes conservantes: cloreto de cálcio, nitrato de cálcio e lactato de cálcio, nas doses $0 \%, 0,5 \%, 1 \%$ e 2\%; e armazenadas nos tempos 0, 10, 20 e 30 dias, em que a dose $0 \%$ todos os conservantes caracteriza o tratamento controle (adicional).

Palavras-chave: análise de variância, software $R$, estatística experimental.

\section{INTRODUCTION}

In applied sciences, such as agricultural sciences, experimentation is particularly important (ANDRIAZZI, 2007). Using it, one can determine the best dose of fertilizer to be applied to the soil for a given culture to have maximum productivity and to know the ideal period to harvest a fruit, in order to provide the most appreciated flavor, or the best type of pruning for a perennial culture for a larger yield (ARAÚJO et al., 2007; BRUNETTO et al., 2008).

An example of area where experimentation is very useful is the fruit culture, particularly for growing grapevines, for table grapes or grapes for winemaking. In Brazil, the South, Southeast and Northwest regions are the regions where the grape cultivation is more effective, where each cultivar is produced for a particular purpose. In the South, grape production is destined for the production of wines and juices, while the southwestern region consumes grape in natura. In the Northeast, the most of the production is for table grapes (ELIAS, 2008).

There are over 60,000 varieties of grapes around the world, among them there are Merlot, Sayra, Cabernet Sauvignon and Niagara. In particular, the Niagara grape is the most widely produced in Brazil, mainly in the northwest of the state of São Paulo.It has low production cost to be somewhat susceptible to diseases caused by fungi (BOTELHO et al., 2004).The Niagara is the main

'Faculdade de São Lourenço, São Lourenço, MG, Brasil.

IIUniversidade Federal de Alfenas (Unifal-MG), 37130-000, Alfenas, MG, Brasil. E-mail: eric.ferreira@unifal-mg.edu.br. "Corresponding author. 
Brazilian table grape and it has compact medium bunch delicate berries (GOMES \& FERRAZ, 2011).

On the other hand, the grape has high perishability, which causes economic losses to growers, since the postharvest loss is estimated around $20-95 \%$ (ELIAS, 2008). Therefore, combining preservative processes in pre or post-harvest might be important. In these cases, the use of substances to prolong the postharvest life has become an alternative.

In fruit culture and other areas of agricultural sciences, there are experiments whose designs and schemes can lead to tricky analysis. For instance, one can study the effect that cultivars, soil fertilization rates, foliar fertilization and harvest seasons have on the characteristics of the fruit, such as sugar content, $\mathrm{pH}$, content of total solids, soluble solids, among others.

For these and other reasons, it is not uncommon the designs, statistical models and hence the analysis to become complex, what demands constant research. An example of a relatively complex experimental situation is the split double factorial experiment with a single additional treatment in the plot (BEZZERRA NETO et al., 2005; VIDAL NETO et al., 2005; YASSIN et al., 2002). This additional treatment is an extra or control treatment and is conducted within the experiment, but it is analyzed separately by contrast against the test treatments (HEALY, 1956).

In these situations, the analysis requires the researcher to perform several runs using popular software such as Sisvar (FERREIRA, 2000), Assistat (SILVA \& AZEVEDO, 2006) and R (R CORE TEAM, 2014), and complement these analyses on his/her own, making the whole procedure more difficult and uncertain. Namely, it is required to combine results of regular double factorials, triple factorials, regular split-plot design and single factor one-way ANOVA for providing the necessary source of variation.

The objectives of this research are: (i) discuss and explain how to deal with the analysis of experiments conducted in completely randomized design (CRD) and split double factorial design with additional treatment in the plot; (ii) program a function able to perform such analysis in a single run, using R language (R CORE TEAM, 2014); and (iii) illustrate the discussion analyzing data from an experiment on post-harvest of Niagara grapes.

\section{MATERIAL AND METHODS}

Data from the experiment with Niagara (Vitislabrusca) grapes were kindly provided by Dr.
Heloisa Helena de Siqueira, pos-doc fellow at the Universidade Federal de Lavras, Brazil, in order to demonstrate the analysis of experiments conducted in completely randomized design (CRD) and split double factorial design with additional treatment in the plot and also the function set in R code (R CORE TEAM, 2014).

Grapes were treated in the pre-harvest with three preservatives: calcium chloride, calcium nitrate and calcium lactate at $0 \%, 0.5 \%, 1 \%$ and $2 \%$, and stored at $0,10,20$ and 30 days. All the preservatives evaluated at $0 \%$ represented the control (additional) treatment. Thus, the experiment features a split double factorial with additional treatment in the plot $(3 \times 3+1) \times 4$, under 3 replications.

\section{RESULTS AND DISCUSSIONS}

Let a triple factorial experiment conducted in CRD with factors $\alpha, \beta$ and $\gamma$ considered in $a, b$ and $c$ levels, respectively, replicated $J$ times. Also, consider that these three factors are arranged in split-plot scheme with the double factorial formed by $\alpha$ and $\beta$, allocated in the plot, and the factor $\gamma$, in the subplot. Finally, consider additional treatment allocated in the plot, which contains the $c$ levels of $\gamma$ and is also replicated $J$ times.

As a first result of this research, it was sketched the layout of the randomization of the experiment (Figure 1) which has a split double factorial in CRD with an additional factor. In the plot one can see the combination of factors $\alpha$ and $\beta$ levels or the additional treatment. On the other hand, in the subplot, the $c$ levels of factor $\gamma$ can be found.

From this arrangement, one can note that sources of variation involved come, at a first sign,

\begin{tabular}{|c|c|c|c|c|}
\hline$\left(\alpha_{1} \beta_{b}\right)_{J}$ & & $A d_{2}$ & & $\left(\alpha_{1} \beta_{1}\right)_{J}$ \\
\hline \begin{tabular}{l|l|l|l|l|l|l}
$\gamma_{1}$ & $\gamma_{2}$ & $\ldots$ & $\gamma_{c}$
\end{tabular} & & \begin{tabular}{l|l|l|l}
$\gamma_{1}$ & $\gamma_{2}$ & $\ldots$ & $\gamma_{c}$
\end{tabular} & & \begin{tabular}{l|l|l|l|}
$\gamma_{1}$ & $\gamma_{2}$ & $\ldots$ & $\gamma_{c}$ \\
\end{tabular} \\
\hline & & $\left(\alpha_{a} \beta_{b}\right)_{j}$ & & \\
\hline & & \begin{tabular}{l|l|l|l|l}
$\gamma_{1}$ & $\gamma_{2}$ & $\ldots$ & $\gamma_{e}$
\end{tabular} & & \\
\hline$\left(\alpha_{1} \beta_{1}\right)_{1}$ & & & & $\left(\alpha_{a} \beta_{1}\right)_{1}$ \\
\hline \begin{tabular}{l|l|l|l}
$\gamma_{1}$ & $\gamma_{2}$ & $\ldots$ & $\gamma_{c}$
\end{tabular} & & & & \begin{tabular}{l|l|l|l|}
$\gamma_{1}$ & $\gamma_{2}$ & $\ldots$ & $\gamma_{c}$ \\
\end{tabular} \\
\hline & $A d_{1}$ & & $\left(\alpha_{a} \beta_{b}\right)_{4}$ & \\
\hline & \begin{tabular}{|l|l|l|l|}
$\gamma_{1}$ & $\gamma_{2}$ & $\ldots$ & $\gamma_{c}$ \\
\end{tabular} & & \begin{tabular}{l|l|l|l|}
$\gamma_{1}$ & $\gamma_{2}$ & $\ldots$ & $\gamma_{c}$ \\
\end{tabular} & \\
\hline$\left(\alpha_{a} \beta_{1}\right)_{j}$ & & $\left(a_{1} \beta_{b}\right)_{1}$ & & $A d_{j}$ \\
\hline \begin{tabular}{|l|l|l|l}
$\gamma_{1}$ & $\gamma_{2}$ & $\ldots$ & $\gamma_{0}$
\end{tabular} & & \begin{tabular}{l|l|l|l|}
$\gamma_{1}$ & $\gamma_{2}$ & $\ldots$ & $\gamma_{c}$ \\
\end{tabular} & & \begin{tabular}{l|l|l|l|}
$\gamma_{1}$ & $\gamma_{2}$ & $\ldots$ & $\gamma_{c}$ \\
\end{tabular} \\
\hline $\begin{array}{r}\text { Figure } 1 \text { - Il } \\
\\
\text { re } \\
\\
\text { cd } \\
\beta\end{array}$ & $\begin{array}{l}\text { ustration of } \\
\text { plications of } \\
\text { ming from } \\
\beta_{2}, \ldots, \beta_{b} \text {, and } \\
\text { ditional treat }\end{array}$ & $\begin{array}{l}\text { a split doubl } \\
\text { f a double } \\
\text { combinatic } \\
c \text { levels of } \\
\text { tment in the }\end{array}$ & $\begin{array}{l}\text { factorial ir } \\
\text { actorial, wi } \\
\text { ns of } \alpha_{1} \\
\gamma \text { in the sub } \\
\text { lot }\left(A d_{p}\right) .\end{array}$ & $\begin{array}{l}\text { CRD with } J \\
\text { th treatments } \\
\alpha_{2}, \ldots, \alpha_{a} \text { and } \\
\text { plots, with an }\end{array}$ \\
\hline
\end{tabular}


either from the plots or the subplots. Regarding the plots, one can subdivide it into several sources variation: factor $\alpha$, factor $\beta$, interaction $\alpha \beta$ and contrast between the treatment and additional treatment allocated in the plot $A d$. In turn, the variation in the subplots, can be divided in: factor $\gamma$, double interactions $\gamma \alpha$ and $\gamma \beta$, triple interaction $\alpha \beta \gamma$ and contrast between additional treatment and subplot treatments. This way of designing the experiment leads to the following statistical model:

$Y_{j \mu k}=\mu+\alpha_{i}+\beta_{j}+(\alpha \beta)_{y}+A d_{p}+e_{A}+\gamma_{k}+(\alpha \gamma)_{k+}+(\beta \gamma)_{k k}+(\alpha \beta \gamma)_{j k}+A d_{s}+e_{k}$

with $i=1,2, \ldots, a ; j=1,2, \ldots, b ; k=1,2, \ldots, c$ and $l=1,2, \ldots, J$; where $Y_{i j k l}$ is the $l$-th repetition of the plot subject to the level $i$ of factor $\alpha$, to the level $j$ of factor $\beta$ and the level $k$ of factor $\gamma ; \mu$ is a common constant to all observations; $\alpha_{i}$ the effect of the $i$-th level of factor $\alpha$; $\beta_{\mathrm{j}}$ is the effect of the $j$-th level of factor $\beta ;(\alpha \beta)_{\mathrm{ij}}$ is the interaction of $\alpha_{i}$ and $\beta_{\mathrm{j}}$; $A d_{p}$ is the contrast between the additional treatment and double factorial; $e_{A}$ is the error associated to the plot; $\gamma_{k}$ is the effect of $k$-th level of the factor $\gamma ;(\alpha \gamma)_{i k}$ is the interaction of $\alpha_{i}$ and $\gamma_{k}$; $(\beta \gamma)_{\mathrm{jk}}$ is the interaction of $\beta_{\mathrm{j}}$ and $\gamma_{\mathrm{k}} ;(\alpha \beta \gamma)_{\mathrm{ijk}}$ is the triple interaction between $\alpha_{\mathrm{i}}, \beta_{\mathrm{j}}$ and $\gamma_{\mathrm{k}} ; A d_{s}$ is the contrast between the additional treatments and the subplots; $e_{B}$ is the random error associated with subplots. All terms but the errors are considered fixed, leading to a fixed model; and $e_{A} \sim N\left(0, \sigma_{A}^{2}\right)$ and $e_{B} \sim N\left(0, \sigma_{B}^{2}\right)$.

Given the statistical model is easy to get how the analysis of variance table should be built. Its sources of variation and respective degrees of freedom, sums of squares, mean squares and computed $F$ 's are given in table 1 .

It is worth noting that the interpretation of the contrast between the additional treatment and subplot treatments $(A d)$ is not straightforward established, since the additional treatment contains the $c$ level of $\gamma$ within itself. Therefore, it is advised that this effect can be confounded with the error $B$, inflating the latter and increasing a unit in degrees of freedom. Let $e_{B}^{*}=e_{B}+A d_{s}$ be the new error. Given this confounding, both statistical model and the framework of analysis of variance are reduced, to:

$Y_{i j k l}=\mu+\alpha_{i}+\beta_{j}+(\alpha \beta)_{i j}+A d_{p}+e_{A}+\gamma_{k}+(\alpha \gamma)_{i k}+(\beta \gamma)_{j k}+(\alpha \beta \gamma)_{j i k}+e_{B}^{*}$

where all the effects are as previously described and the new table of variance is in table 2 .

Regarding the plots, it is easy to estimate the contrast between the factorial average and the additional treatment, and get all conclusions usually provided by a split double factorial.

Under this framework, one derives the sums of squares of the sources of variation, inspired by BANZATTO and KRONKA (2006). The corrected overall sum of squares $\left(S Q_{T}\right)$ in this case is given by: $S Q_{T}=\sum_{i=1}^{c} \sum_{j=1}^{b} \sum_{k=1}^{c} \sum_{l=1}^{J} Y_{i j k l}^{2}+\sum_{k=1}^{c} \sum_{l=1}^{J} A d_{k l}^{2}-C o^{*}$, where $C^{*}=\frac{\left(\sum_{i, j, k, j} y_{j k j l}+\sum_{k, l} A d_{k i}\right)^{2}}{(a b+1) c J}$ is the quadratic mean, also called correction.

The $\alpha$ and $\beta$ sum of squares are given respectively by $S Q_{\alpha}=\frac{\sum_{i=1}^{a} A_{i}^{2}}{b c J}-C o$ and $S Q_{\beta}=\frac{\sum_{j=1}^{b} B_{j}^{2}}{a c J}-C o$, where $A_{i}$ and $B_{j}$ are the totals of the levels $i$ and $j$ of $\alpha$ and $\beta$, respectively, and the other correction $C o$ is given by: $C o=\frac{\left(\sum_{i, j, k, l} y_{i j k l}\right)^{2}}{a b c J}$

For $\gamma$ sum of squares it is necessary to consider the additional treatment (sum of squares that makes up the subplot): $S Q_{\gamma}=\frac{\sum_{k=1}^{c}\left(C_{F a_{k}}^{2}+C_{A d_{k}}^{2}\right)}{(a b+1) J}-C o^{*}$, where $C_{\text {Fat }_{K}}$ is the total of the $k$-th level of the factor $\gamma$ within the factorial and $C_{A d_{k}}$ is total of the k-th level of the factor $\gamma$ within the additional treatment.

The sum of squares of the interaction $\alpha \beta$ is obtained from the difference between the sum of squares of the treatments from the double factorial and the sums of squares of such factors, as: $S Q_{\alpha \beta}=\frac{\sum_{i, j}^{a, b} A B_{i j}^{2}}{c J}-C o-S Q_{\alpha}-S Q_{\beta}$, where $A B_{i j}$ is the total of the plots receiving $\alpha_{i}$ and $\beta_{j}$.

Similarly, the sums of squares of the interactions $\alpha \gamma$ and $\beta \gamma$ can be obtained, respectively, by: $S Q_{\alpha \gamma}=\frac{\sum_{i, k}^{a, c} A C_{i k}^{2}}{b J}-C o-S Q_{\alpha}-S Q_{\gamma} \quad$ and $S Q_{\beta \gamma}=\frac{\sum_{j, k}^{b, c} B C_{j k}^{2}}{a J}-C o-S Q_{\beta}-S Q_{\gamma}$, where $A C_{i k}$ and $B C_{j k}$ are, respectively, the total of the treatments generated by the factorial combination of $\alpha$ and $\gamma$, and $\beta$ and $\gamma$.

The triple interaction $\alpha \beta \gamma$ can also be obtained by difference. It is the difference between the sum of squares of treatments obtained by the factorial combination of $\alpha, \beta$ and $\gamma$, and simple effects and double interactions, as: $S Q_{\alpha \beta \gamma}=\frac{\sum_{i, j, k}^{a, b, c} A B C_{i j k}^{2}}{J}-C o-S Q_{\alpha}-S Q_{\beta}-S Q_{\gamma}-S Q_{\alpha \beta}-S Q_{\alpha \gamma}-S Q_{\beta \gamma}$

where $A B C_{i j k}$ is the total of the $i j k$-th treatment (combining levels of $\alpha, \beta$ and $\gamma$ ).

In turn, the sum of squares of the contrast between the additional treatment and the factorial average is given by:

$$
S Q_{A d_{P}}=\frac{\hat{Y}^{2}}{J \sum z_{i}^{2}}=\frac{\hat{Y}^{2}}{J\left((a b)^{2}+(-1)^{2}+(-1)^{2}+\ldots+(-1)^{2}\right)}=\frac{\hat{Y}^{2}}{J\left((a b)^{2}+a b\right)}
$$


Table 1 - Table of analysis of variance with the sources of variation, degrees of freedom, sum of squares, mean squares and $F^{\prime} s$ calculated.

\begin{tabular}{|c|c|c|c|c|}
\hline $\mathrm{FV}$ & GL & SQ & QM & $\mathrm{F}_{\mathrm{c}}$ \\
\hline$\alpha$ & $a-1$ & $S Q_{\alpha}$ & $\frac{S Q_{\alpha}}{g l_{\alpha}}$ & $\frac{Q M_{\alpha}}{Q M_{R_{a}}}$ \\
\hline$\beta$ & $b-1$ & $S Q_{\beta}$ & $\frac{S Q_{\beta}}{g l_{\beta}}$ & $\frac{Q M_{\beta}}{Q M_{R_{a}}}$ \\
\hline$\alpha \beta$ & $(a-1)(b-1)$ & $S Q_{\alpha \beta}$ & $\frac{S Q_{\alpha \beta}}{g l_{a \beta}}$ & $\frac{Q M_{\alpha \beta}}{Q M_{R_{a}}}$ \\
\hline$A d_{p}$ & 1 & $S Q_{A d_{p}}$ & $\frac{S Q_{A d_{p}}}{g l_{A d_{n}}}$ & $\frac{Q M_{A d_{p}}}{Q M_{R_{n}}}$ \\
\hline Error $A$ & $(J-1) a b+J-1$ & $S Q_{R_{a}}$ & $\frac{S Q_{R_{a}}}{g l_{R_{a}}}$ & \\
\hline Plot & $(a b+1) J-1$ & $S Q_{P}$ & $\frac{S Q_{P}}{g l_{P}}$ & \\
\hline$\gamma$ & $c-1$ & $S Q_{\gamma A d}$ & $\frac{S Q_{\gamma A d}}{g l_{\gamma}}$ & $\frac{Q M_{\gamma}}{Q M_{R_{h}}}$ \\
\hline$\alpha \gamma$ & $(a-1)(c-1)$ & $S Q_{\alpha \gamma}$ & $\frac{S Q_{\alpha \gamma}}{g l_{\alpha \gamma}}$ & $\frac{Q M_{\alpha \gamma}}{Q M_{R_{h}}}$ \\
\hline$\gamma \beta$ & $(b-1)(c-1)$ & $S Q_{\beta \gamma}$ & $\frac{S Q_{\beta \gamma}}{g l_{\beta \gamma}}$ & $\frac{Q M_{\beta \gamma}}{Q M_{R_{h}}}$ \\
\hline$\alpha \beta \gamma$ & $(a-1)(b-1)(c-1)$ & $S Q_{\alpha \beta \gamma}$ & $\frac{S Q_{\alpha \beta \gamma}}{g l_{\alpha \beta \gamma}}$ & $\frac{Q M_{\alpha \beta \gamma}}{Q M_{R_{h}}}$ \\
\hline$A d_{s}$ & 1 & $S Q_{A d_{s}}$ & $\frac{S Q_{A d_{s}}}{g l_{A d_{s}}}$ & $\frac{Q M_{A d_{s}}}{Q M_{R_{b}}}$ \\
\hline Error $B$ & $(c-1)[a b(J-1)+J]-1$ & $S Q_{R_{b}}$ & $\frac{S Q_{R_{b}}}{g l_{R_{b}}}$ & \\
\hline Total (corrected) & $(a b+1) c J-1$ & $S Q_{T}$ & $\frac{S Q_{T}}{g l_{T}}$ & \\
\hline
\end{tabular}

where $\hat{Y}=a b A d-\left(A B_{11}+A B_{12}+\ldots+A B_{a b}\right)$ is the contrast of total additional treatment $A d_{p}$ combining the totals of the plot treatments $A_{i}$ and $B_{i}$, and $Z_{i}$ are the coefficients of the combination of the total of $A_{i}$ and $B_{j}$. The plots sum of squares can be described as follows: $S Q_{P}=\frac{\sum_{i, j, l}^{a, b, j} A B_{i j l}^{2}+\sum_{l}^{J} A d_{l}^{2}}{c}-C o^{*}$, where $A B_{i j l}$ is the total of each replication of $A B_{i j}$.
Finally, the sum of the squares of the first error $\left(e_{A}\right)$ may also be obtained from the difference between the plots sum of squares and other sources of variation present in the plot, namely:

$S Q_{e_{A}}=S Q_{P}-S Q_{\alpha}-S Q_{\beta}-S Q_{\alpha \beta}-S Q_{A d_{p}}$

Similarly, the sum of squares of the second error $\left(e_{B}\right)$ is obtained by difference between the overall sum of squares $\left(S Q_{T}\right)$, plots sum of square $\left(S Q_{P}\right), \gamma$ sum of squares and its interactions: 
$S Q_{e_{B^{*}}}=S Q_{T}-S Q_{P}-S Q_{\gamma}-S Q_{\alpha \gamma}-S Q_{\beta \gamma}-S Q_{\alpha \beta \gamma}$

The whole analysis of variance table is straightforward, given the sum of squares, degrees of freedom and mean squares.

The function sub.fat.ad() allows to analyze a split double factorial in CRD with one additional treatment, through analysis of variance. It receives ten arguments, as follows: sub. fat.ad(factor1, factor2, factor3, addit, rep, resp, quali $=\mathrm{c}(\mathrm{T}, \mathrm{T}, \mathrm{T})$, fac.names=c ( $\left.F 1^{\prime},{ }^{\prime} \mathrm{F} 2^{\prime}{ }^{\prime}, \mathrm{I}^{\prime} 3^{\prime}\right)$, sigF=0.05, where factor 1 , factor 2 and factor 3 are vectors containing the levels of

Table 2 - Analysis of variance table confounding $A d_{s}$ in the error $B$.

\begin{tabular}{|c|c|c|c|c|}
\hline $\mathrm{FV}$ & GL & SQ & QM & $\mathrm{F}_{\mathrm{c}}$ \\
\hline$\alpha$ & $a-1$ & $S Q_{\alpha}$ & $\frac{S Q_{\alpha}}{g l_{\alpha}}$ & $\frac{Q M_{\alpha}}{Q M_{R_{a}}}$ \\
\hline$\beta$ & $b-1$ & $S Q_{\beta}$ & $\frac{S Q_{\beta}}{g l_{\beta}}$ & $\frac{Q M_{\beta}}{Q M_{R_{a}}}$ \\
\hline$\alpha \beta$ & $(a-1)(b-1)$ & $S Q_{\alpha \beta}$ & $\frac{S Q_{\alpha \beta}}{g l_{a \beta}}$ & $\frac{Q M_{\alpha \beta}}{Q M_{R_{a}}}$ \\
\hline$A d_{p}$ & 1 & $S Q_{A d_{p}}$ & $\frac{S Q_{A d_{p}}}{g l_{A d_{p}}}$ & $\frac{Q M_{A d_{p}}}{Q M_{R_{a}}}$ \\
\hline Error $A$ & $(J-1) a b+J-1$ & $S Q_{R_{a}}$ & $\frac{S Q_{R_{a}}}{g l_{R_{a}}}$ & \\
\hline Plot & $(a b+1) J-1$ & $S Q_{P}$ & $\frac{S Q_{P}}{g l_{P}}$ & \\
\hline$\gamma$ & $c-1$ & $S Q_{\gamma A d}$ & $\frac{S Q_{\gamma A d}}{g l_{\gamma}}$ & $\frac{Q M_{\gamma}}{Q M_{R_{b}}}$ \\
\hline$\alpha \gamma$ & $(a-1)(c-1)$ & $S Q_{\alpha \gamma}$ & $\frac{S Q_{\alpha \gamma}}{g l_{\alpha \gamma}}$ & $\frac{Q M_{\alpha \gamma}}{Q M_{R_{b}}}$ \\
\hline$\gamma \beta$ & $(b-1)(c-1)$ & $S Q_{\beta \gamma}$ & $\frac{S Q_{\beta \gamma}}{g l_{\beta \gamma}}$ & $\frac{Q M_{\beta \gamma}}{Q M_{R_{b}}}$ \\
\hline$\alpha \beta \gamma$ & $(a-1)(b-1)(c-1)$ & $S Q_{\alpha \beta \gamma}$ & $\frac{S Q_{\alpha \beta \gamma}}{g l_{\alpha \beta \gamma}}$ & $\frac{Q M_{\alpha \beta \gamma}}{Q M_{R_{b}}}$ \\
\hline Error $B$ & $(c-1)[a b(J-1)+J]$ & $S Q_{R_{b}}$ & $\frac{S Q_{R_{b}}}{g l_{R_{b}}}$ & \\
\hline Total & $(a b+1) c J-1$ & $S Q_{T}$ & $\frac{S Q_{T}}{g l_{T}}$ & \\
\hline
\end{tabular}


the factors 1, 2 and 3 (which, in the experiment with Niagara grapes are, respectively, the factors $\alpha, \beta$ and $\gamma$ ); addit contains the additional treatment; rep contains the replications indices; resp contains the response variable (for the three factors); quali=C $(T, T, T)$ is a logical variable, if TRUE (default), where respective factor is qualitative; otherwise, quantitative; fac.names are labels for factors 1, 2 and 3; sig $F$ is the significance for $F$ test (the default is $5 \%$ ).

To illustrate the behavior of Niagara grapes during storage (factor $\gamma$ ), under several combinations of kinds of preservatives (factor $\alpha$ ) and doses (factor $\beta$ ), four physicochemical variables were picked up, namely $\mathrm{pH}$, firmness (Table 3), total sugar and phenolic acids content, whose results will be discussed below. All analysis were performed using function sub.fat. ad (), in R software (R CORE TEAM, 2014). Assumptions of normality, homoscedasticity and independence were satisfied.

Those physicochemical variables were significantly affected by the factor time. There was a reduction in firmness, total sugar and phenolic acids content along time $(\mathrm{P}=0.0192$, $\mathrm{P}<10^{-4}, \mathrm{P}<10^{-4}$, respectively), while $\mathrm{pH}$ slightly increased $\left(\mathrm{P}<10^{-4}\right)$. Regarding the preservatives, they were considered statistically similar for $\mathrm{pH}$ $(\mathrm{P}=0.4249)$. For firmness, calcium nitrate and calcium chloride provided the firmest berries $(\mathrm{P}=0.0203)$. On the other hand, the highest level of phenolic acids and total sugar was provided by calcium chloride and calcium lactate (both $\left.\mathrm{P}<10^{-4}\right)$. Note that calcium chloride had the best overall behavior.

Finally, the doses of preservatives were considered statistically similar for $\mathrm{pH}$ and firmness $(\mathrm{P}=0.1002$ and $\mathrm{P}=0.9928$, respectively). For total sugar and phenolic acids, the dose $1 \%$ provided the highest content (both $\mathrm{p}<10^{-4}$ ). Therefore, $1 \%$ seems to provide good results for all variables.

\section{CONCLUSION}

Split double factorial designs with an additional treatment in the plot raise when researchers plan an experiment along time (for instance) and, at the same time, want to study two other factors, which absence of one factor or its null level leads to the same treatment. The way this design is approached in this paper allows the researcher to analyze such experiments in a single run, particularly, using the function sub. fat. $\mathrm{ad}()$. In the experiments with Niagara grapes presented here, the time of storage affected the fruits significantly in different ways, as expected. As preservative, calcium chloride is recommended to be used at dose $1 \%$.

Table 3 - Output of function sub.fat.ad(): analysis of variance table for the physicochemical variable firmness.

\begin{tabular}{lccccc}
\hline FV & GL & SQ & QM & Fc & Pr>Fc \\
\hline PRESERVATIVE & 2 & 0.029563 & 0.014782 & 3.504 & 0.0496 \\
DOSE & 2 & 0.000052 & 0.000026 & 0.006 & 0.9940 \\
PRESERVATIVE*DOSE & 4 & 0.014093 & 0.003523 & 0.835 & 0.5189 \\
Ad - fat & 1 & 0.000926 & 0.000926 & 0.219 & 0.6449 \\
Error A & 20 & 0.084383 & 0.004219 & & \\
PLOT & 29 & 0.129017 & 0.004449 & & 0.0000 \\
TIME & 3 & 0.038700 & 0.012900 & 9.736 & 0.0540 \\
PRESERVATIVE*TIME & 6 & 0.017533 & 0.002922 & 2.205 & 0.0031 \\
DOSE*TIME & 6 & 0.029667 & 0.004945 & 3.732 & 0.3583 \\
PRESERVATIVE*DOSE*TIME & 12 & 0.017856 & 0.001488 & 1.123 & \\
Error B & 63 & 0.083477 & 0.001325 & & \\
Total (corrected) & 119 & 0.316250 & & & \\
\hline
\end{tabular}




\section{ACKNOWLEDGEMENTS}

Special acknowledgements to Conselho Nacional de Desenvolvimento Científico e Tecnológico (CNPq) and Fundação de Amparo à Pesquisa do Estado de Minas Gerais (FAPEMIG).

\section{REFERENCES}

ANDRIAZZI, C.V.G. Adequação da metodologia do teste de frio para avaliação do vigor de sementes de sorgo. 2007. $28 \mathrm{f}$. Dissertação (Mestrado em Agronomia/Fitotecnia) - Instituto de Ciência Agrárias, Universidade Federal de Uberlândia, Uberlândia, MG.

DE ARAÚJO, E.N. et al. Produção do pimentão adubado com esterco bovino e biofertilizante. Revista Brasileira de Engenharia Agrícola Ambiental, Campina Grande, v.11, n.5, p.466-470, 2007.

BANZATTO, D.A.; KRONKA, S.N. Experimentação agrícola. Jaboticabal: FUNEP, 2006. 249p

BEZERRA NETO, F. et al. Sombreamento para produção de mudas de alface em alta temperatura e ampla luminosidade. Horticultura Brasileira, Brasília, v.23, n. 1, p. 133-137, 2005.

BOTELHO, R.V. et al. Efeitos de reguladores vegetais na qualidade de uvas 'Niagara Rosada' na região noroeste do estado de São Paulo. Revista Brasileira de Fruticultura, Jaboticabal, v.26, n.1, p.74-77, 2004.

BRUNETTO, G. et al. Produção, composição da uva e teores de nitrogênio na folha e no pecíolo em videiras submetidas à adubação nitrogenada. Ciência Rural [online], Santa Maria, v.38, n.9, p.2622-2625, 2008

ELIAS, H.H.S. Caracterização física, química e bioquímica de cultivares de videira durante a maturação. 2008. 74f. Tese (Doutorado em Ciência dos Alimentos) - Departamento de Ciência dos Alimentos, Universidade Federal de Lavras, Lavras, MG.

FERREIRA, D. Análises estatísticas por meio do Sisvar para Windows versão 4.0. In: REUNIÃO ANUAL DA REGIÃO BRASILEIRA DA SOCIEDADE INTERNACIONAL DE BIOMETRIA, 45., 2000, São Carlos, SP. Programas e resumos... São Carlos, SP: UFSCar, 2000. p.255-258.

GOMES, D.; FERRAZ, A.C. de O. Mechanical behavior of 'Niagara Rosada' grape berry detachment. Engenharia Agrícola, Jaboticabal, v.31, n.6, p.1115-1122, 2011.

R CORE TEAM. R: a language and environment for statistical computing. Vienna, Austria: $\mathrm{R}$ Foundation for Statistical Computing. 2014

SILVA, F. de A.S.; DE AZEVEDO, C.A.V. A new version of the assistat-statistical assistance software. In: WORLD CONGRESS ON COMPUTERS IN AGRICULTURE, 4, Orlando-FL-USA. Anais... Orlando: American Society of Agricultural Engineers, 2006. p.393-396.

VIDAL NETO, F.C. et al. Mutantes morfológicos de algodoeiro herbáceo como fonte de resistência ao bicudo. Pesquisa Agropecuária Brasileira, Brasília, v.40, n.2, p.123-128, 2005.

YASSIN, N. et al. Análise de variância em um experimento fatorial de dois fatores com tratamentos adicionais. Ciência e Agrotecnologia, Lavras, Edição Especial, p.1541-1547, 2002. 